\title{
Sonho ou Pseudo Flexibilidade na Cultura Organizacional nos Sistemas de Venda Direta
}

\author{
Amanda Dourado Espíndola ${ }^{1}$, Erlaine Binotto ${ }^{2}$, \\ Elisabete Stradiotto Siqueira ${ }^{3}$, Eduardo Luis Casarotto ${ }^{4}$
}

${ }^{1}$ http://orcid.org/0000-0002-8723-0807 / Universidade Federal da Grande Dourados (UFGD), Brasil
${ }^{2}$ http://orcid.org/0000-0002-0349-4566 / Universidade Federal da Grande Dourados (UFGD), Brasil
${ }^{3}$ http://orcid.org/0000-0002-9957-1393 / Universidade Federal Rural do Semi-árido (UFERSA), Brasil
${ }^{4}$ http://orcid.org/0000-0001-5729-4263 / Universidade Federal da Grande Dourados (UFGD), Brasil

Resumo

A cultura organizacional contribui nos processos de construção da identidade dos membros com a organização. Contudo, em um contexto de flexibilização das relações de trabalho, essa dimensão assume contornos diferenciados. O objetivo foi identificar como os traços da cultura organizacional são traduzidos pelos sujeitos na sua percepção sobre o trabalho. Tratou-se de pesquisa exploratória e qualitativa, que envolveu documentos da organização e entrevistas com dez consultoras de beleza. As categorias de análise foram: 1) perfil, 2) cultura corporativa, 3) políticas em relação às consultoras, 4) relações entre poder e identidade, e 5) adaptação, realização e reconhecimento. Os resultados mostram forte identidade das trabalhadoras com a cultura corporativa. Foram evidenciadas questões como liberdade, flexibilidade de horários, renda extra, qualidade dos produtos, consumo mais barato e reconhecimento. Os traços culturais fortalecem a adesão, principalmente com histórias de sucesso e formas de reconhecimento, havendo forte adesão econômica e valorativa da empresa.

Palavras-chave: subjetividade, poder, identidade.

\section{Dream or Pseudo Flexibility in the Organizational Culture in Direct Sales Systems}

Abstract

Organizational culture contributes to the processes of building the identity of members with an organization. However, in a context of flexible working relationships, this dimension takes on different shapes. The present study aimed to identify the features of organizational culture and how the subjects in their perception of work translate these. It was exploratory and qualitative research, which gathered documents from the organization and interviews with ten beauty consultants. The categories of analysis were 1) profile, 2) corporate culture, 3) company policies and practices in relation to consultants, 4) relations between power and identity, and 5) adaptation, achievement, and recognition. The results show a strong identity of the workers with corporate culture. Issues such as freedom, flexible hours, extra income, product quality and cheaper consumption, as well as recognition. The materials analyzed express cultural traits that strengthen the agreement with the treatment, mainly with success stories and forms of material and symbolic recognition, with strong economic agreement of the company.

Keywords: subjectivity, recognition, identity.

\section{Sueño o Pseudo Flexibilidad en la Cultura Organizacional en los Sistemas de Venta Directa}

Resumen

La cultura organizacional contribuye en los procesos de construcción de identidad de los integrantes con la organización. Sin embargo, en un contexto de relaciones laborales flexibles, esta dimensión asume trazos diferentes. El estudio tuvo como objetivo identificar cómo las características de la cultura organizacional son traducidas por los sujetos en su percepción del trabajo. Esta fue una investigación exploratoria y cualitativa, que contempló documentos de la organización y entrevistas con diez consultoras de belleza. Las categorías de análisis fueron: 1) perfil, 2) cultura corporativa, 3) políticas en relación a las consultoras, 4) relación entre poder e identidad, y 5) adaptación, realización y reconocimiento. Los resultados muestran una fuerte identidad de las trabajadoras con la cultura corporativa. Fueron identificadas cuestiones como la libertad, horarios flexibles, ingresos adicionales, calidad de los productos y consumo más barato, y reconocimiento. Los rasgos culturales fortalecen la adhesión, principalmente con historias de éxito y formas de reconocimiento, habiendo fuerte aceptabilidad económica y valorativa de la empresa. 
A partir do século XX novas formas organizacionais passaram a fazer parte do cenário empresarial. As relações de trabalho predominantemente, regidas por contratos com certa estabilidade, tornam-se diferenciadas e as novas condições de trabalho implicam em diferentes tipos de autonomia. Tal processo sugere maior autonomia, realização dos sujeitos e responsabilidade individual (Alves, 2018).

Essas formas de organização do trabalho conduzem a uma estrutura diferenciada de exercício de poder sobre a força de trabalhado, de forma velada e revestida de controles pouco perceptíveis. Nesse caso a legitimidade do capital advém de uma suposta promessa de autonomia e independência (Tavares, 2015).

Nesse contexto, a cultura organizacional assume um papel importante uma vez que tem a função de construir mecanismos de coesão e adesão ao processo organizacional. Trata-se de estabelecer processos que estabelecem formas de controle, mas ao mesmo tempo, façam com que os trabalhadores sintam que tem autonomia e liberdade em relação ao trabalho. Dessa forma a cultura organizacional está articulada as políticas de gestão de pessoas, uma vez que essas são reflexo dos atributos culturais de cada organização (Raposo, 2020). Se a percepção do controle sobre o trabalho é frágil nos ambientes organizacionais típicos, produtores de bens e serviços, nos sistemas de vendas diretas (SVD) torna-se ainda mais complexo.

Os sistemas de vendas diretas são formas de comercialização feita por revendedores. Sua característica central é a ausência de estabelecimentos comerciais fixos. São estabelecidos no contato pessoal entre vendedor e consumidor. Trata-se de um setor heterogêneo que emprega jovens e adultos que se dedicam, em muitos casos, a atividade como forma de complementação de renda, adequando-se a polivalência necessária para sobreviver em um mercado de trabalho precarizado. O SVD faz parte de um contexto mais amplo do processo de precarização da renda e do trabalho, revestido sobre tons de empreendedorismo e da autonomia do trabalhador que enxerga, neste tipo de trabalho, uma forma de complementação de renda em jornadas de trabalho flexíveis, conciliando suas demandas pessoais e profissionais (Abilio, 2011).

Se por um lado o SVD se insere no contexto de precarização das relações de trabalho, por outro, ao atender as necessidades do trabalhador que não consegue se inserir de forma plena no mercado de trabalho, reveste-se de uma alternativa de um suposto empoderamento desses sujeitos, que perdem os limites entre tempo de trabalho e de não trabalho. "O trabalho das consultoras torna reconhecível o que está em jogo: trabalhadoras-consumidoras que raramente conseguem discernir o quanto ganham por seu trabalho e o quanto investem em consumo dos produtos, quanto tempo dedicam às vendas, em um trabalho imbricado em outras atividades" (Abilio, 2011, p. 20).

Estudo sobre consultoras Natura mostrou que as mesmas justificam as habilidades apoiadas em critérios mercantilistas, ou seja, ser boa vendedora, capaz de induzir alto consumo em suas clientes, alcançar altos níveis de vendas, proporcionar bom retorno financeiro e prestígio, ou seja, boa carreira. São conscientes de que, ter boas relações sociais com a comunidade local, redes de contato e manter clientes valorizados acarretam no aumento do consumo. As premiações representam ritos sociais e demonstram símbolo de sucesso para as mesmas (Vasconcelos \& Vasconcelos, 2003). Este conjunto de práticas organizacionais tem como objetivo expressar, afirmar e comunicar o conteúdo desta rede de significados aos membros da organização (Bedani \& Veiga, 2015). Tais conteúdos tem o potencial de despertar no trabalhador um desejo irresistível, coloca desafios, apresenta a possibilidade de paraíso e as fantasias transbordam (Ronchi, Bandeira, Melo, \& Oliveira, 2016).
As organizações contemporâneas atraem o trabalhador através desses discursos sedutores e tentam interiorizar no indivíduo sua ideologia organizacional. O vínculo entre organização e consultoras envolve um contrato de iniciação, desobrigando a empresa dos direitos e benefícios trabalhistas (Oncken, Pedroso, Sampaio, Barbosa, \& Fischer, 2012). O envolvimento passivo nesses processos de sedução para trabalhos com contornos de precariedade, ainda que em uma relação consentida e aceita, tem na cultura corporativa um papel importante. A cultura organizacional, quando concebida teoricamente como variável da organização, pode ser utilizada como uma ferramenta que potencializa a efetividade organizacional, como uma possibilidade de manipulação de gestores aos seus subordinados, criando relações de identidade com o projeto organizacional (F. C. L. Machado, Maranhão, \& Pereira, 2016). Dessa forma, ao analisar aspectos da socialização, regras que orientam o comportamento, valores, crenças, mitos, ritos, será possível compreender como esse processo adaptação ocorre (Raposo, 2020).

Neste contexto, em que medida a cultura da organização promotora desse tipo de relação, consegue desenvolver estratégias de adaptação que permitam o envolvimento dos sujeitos, com sentimentos positivos de pertencimento e elevada autoestima, apesar das contradições inerentes a esse tipo de trabalho? O objetivo deste artigo é identificar os traços da cultura organizacional e como estes são traduzidos pelos sujeitos na sua percepção sobre o trabalho.

\section{Novas Configurações do Trabalho na Construção dos Traços de Cultura}

As relações entre gênero e trabalho a domicílio tem sustentado desigualdades de renda. Além disso, as mulheres ainda são impelidas a ocupações formais e informais, em tempo parcial, mantendo a duplicidade do trabalho remunerado e atividades domésticas. O trabalho informal, em muitos casos, confunde-se com o espaço produtivo para aquelas que fazem da casa o lugar para obter rendimentos salariais (Guimarães, 2016).

A flexibilidade pode ser compreendida como liberdade e autonomia. Entretanto, uma vertente crítica atribui ao conceito um avanço neoliberal de reorganização do trabalho que incita os indivíduos a amar uma vida pautada pela insegurança. A flexibilidade é um campo perigoso, porque pode oferecer uma ideia de liberdade e autonomia (Hirata, 2015). Tal processo ocorre por técnicas de gerenciamento que não tem enfoque disciplinar, a vigilância não é feita de forma direta, mas sobre os resultados do trabalho (Antunes \& Praun, 2015).

A extensão do controle da dimensão simbólica das organizações na realização dos objetivos tem forte influência dos estudos culturais na década de 1980. Estes decorrem das pesquisas de Schein (1984) que discute a importância do papel do fundador na conformação da cultura organizacional e, de Hofstede (1980), que justifica as diferenças culturais a partir dos contextos nacionais (Barbosa, 2001).

Nas duas perspectivas existe a tentativa de lidar com a dimensão simbólica das organizações, apoiada na produção de uma tecnologia gerencial capaz de desenvolver um método de intervenção na realidade organizacional, de promover vantagem competitiva através de processos de motivação e aglutinação, contribuindo no comprometimento dos colaboradores (Barbosa, 2001). O papel da liderança é de socializar valores que serão compartilhados pelos agentes organizacionais. Valores culturais expressam uma visão de futuro desejada pela cúpula da organização, ou seja, a cultura corporativa que seria promotora de mudanças no sentido desejado. A gestão da cultura estaria orientada pela criação de consensos que 
direcionam o comportamento do grupo.

A perspectiva da integração produz uma concepção de racionalidade superior, que subordina a capacidade interpretativa dos agentes organizacionais, conformando-a e subordinando-a a somente uma dimensão (Hatch, 1997). A respeito desses valores, o indivíduo ao identificar seus valores com os da organização, passa a pensar por meio dela e idealizá-la, sacrificando sua vida pessoal em prol dos objetivos da empresa. Sem que perceba este indivíduo entra "num sistema totalitário, tornado para ele em sagrado transcendente, que legitima sua existência. [...]” (Davel \& Vergara, 2001, p. 175). A cultura corporativa não, necessariamente, consegue modelar valores de forma plena, pois quando concebida como um constructo social constitui-se como resultado de interpretações múltiplas atribuídas pelos sujeitos envolvidos na ação (F. C. L. Machado et al., 2016).

Todavia, há aqueles que incorporam os valores de forma mais intensa. Existem algumas recompensas simbólicas capazes de exercer poder sobre os indivíduos, como "prêmios", "reconhecimentos" e "mudança de nível", "participação nos lucros", "ideia de autonomia" e "estímulo à competição e colaboração entre colegas" (Siqueira, 2006, p. 43-44).

Os símbolos implantados pela empresa a respeito do significado de conseguir algo geram nos colaboradoras um sentido para suas ações. Eles deixam, por exemplo, de encarar um pin como simples acessório, desenvolvendo um sentimento de "ser diferenciado", quem sabe superior, apenas por portar um acessório oferecido pela organização. Isso vai muito além do valor do reconhecimento, mais do que ele representa para o indivíduo e para o grupo social ao seu redor. Mais importante do que receber o objeto, é o grupo social, ao seu redor, entender o significado desse reconhecimento repleto de simbologias (Davel \& Vergara, 2001).

Outra forma de construção da identidade cultural ocorre por meio de treinamentos e regulamentos. A organização doutrina seus colaboradores, para disseminar suas políticas e diretrizes de forma sistemática e igualitária (Reis \& Azevedo, 2015). Dessa forma, é possível identificar como os treinamentos ajudam a internalizar valores e condutas nos colaboradores.

Políticas de recursos humanos têm papel importante na construção da identidade organizacional e na adaptação de seus membros a tal proposição. Ao analisar as estratégias de seleção, treinamento e retenção de pessoas é possível delinear traços da cultura organizacional (Reis \& Azevedo, 2015). A confluência do trabalho de uma pessoa (tarefa), as aspirações de carreira, os valores pessoais e o estilo de vida (interesses pessoais) podem se constituir em formas que permitam maior ou menor adaptação a cultura organizacional (Morgan, 2007). Com isso, a organização estimula as forças produtivas do indivíduo, ao proporcionar "responsabilidades, satisfações morais, trabalho interessante, momentos de prazer" e simultaneamente, conseguir controlar essa capacidade produtiva dos colaboradores para atingir os "objetivos da empresa” (Pagès, Bonetti, De Gaulejac,\& Descendre, 1987, p. 27-28).

Por meio da cultura da organização e de seus padrões de conduta, a empresa uniformiza o comportamento dos colaboradores, além de se projetar na vida pessoal deles, de modo que estes não consigam se desvincular da empresa, como se fossem "fantoches" presos a linhas imaginárias (Pinto, 2011). Quanto mais envolvidos emocionalmente com a organização, menor será a capacidade do colaborador para identificar aspectos negativos na empresa, pois existe a necessidade de preservar uma imagem "magnífica" e "perfeita" da organização (Souza, Oliveira, \& Da Silva, 2015). Algumas categorias conceituais do discurso organizacional, adotado pela gestão de pessoas, são entendidas como parte de um jogo sedutor, pois convida o trabalhador a entregar-se de corpo e alma ao trabalho na, e pela organização, portanto há sedução no campo do discursivo (Vieira, 2014).

\section{Método}

\section{Participantes}

Foram entrevistadas dez consultoras de diferentes níveis hierárquicos, ocupantes dos cargos: consultora de beleza (4); consultora sênior (1); iniciadora estrela (1); futura diretora (1); diretora em qualificação (1); e diretora (2), de uma empresa multinacional de vendas diretas com nome fictício de Pink Dream em Dourados, MS, denominadas de R1 a R10.

\section{Instrumentos}

Trata-se de uma pesquisa exploratória e documental, com análise qualitativa. Foi utilizada entrevista semiestruturada tendo como referência as adotadas por Pinto (2011) e Souza et al. (2015).

\section{Procedimentos de Coleta de Dados e Cuidados Éticos}

O acesso a essas consultoras se deu por meio de uma lista de contatos fornecida, com grupos de consultoras da marca, adotando a técnica de bola de neve. Nove entrevistas foram presenciais e uma por telefone, durante os meses de janeiro e fevereiro de 2018. Selecionou-se consultoras atuantes, que tivessem participado de treinamentos na empresa e que conhecessem a cultura da mesma, com critérios de acessibilidade e exaustão.

Para facilitar o entendimento sobre o funcionamento e as ferramentas utilizadas pela organização, bem como suas regras, procedimentos e filosofia, foi realizada uma análise documental. Essa análise considerou dados fornecidos pela empresa: informações institucionais abertas e informações, materiais e treinamentos disponíveis apenas para os consultores da marca. As entrevistas foram gravadas em áudio mediante autorização das entrevistadas e, em média, duraram 28 minutos. Posteriormente, foram transcritas mantendo as expressões e gírias, ou seja, de forma naturalizada.

\section{Procedimentos de Análise de Dados}

As categorias de análise: perfil das entrevistadas (flexibilidade, renda extra e autonomia); cultura corporativa (formalização dos valores desejados); políticas e práticas da empresa em relação às consultoras (adaptação à cultura organizacional); relações entre poder e identidade no processo de gestão; adaptação, realização e reconhecimento. Para análise considerou-se a frequência de respostas e de forma interpretativa o seu conteúdo. Quanto à análise dos documentos, buscou-se identificar elementos que pudessem auxiliar a caracterizar as categorias propostas.

\section{Resultados e Discussão}

\section{Perfil das Entrevistadas: Flexibilidade, Renda Extra e Autonomia}

Mulheres possuíam idade entre 19 e 50 anos e com níveis de escolaridade, predominantes, em superior incompleto e superior completo. Seis consultoras eram casadas, três solteiras e uma em união estável. As casadas com filhos (dois (4), três (2) e um (1)), uma mãe solteira e, uma grávida em união estável. Para as sete com filhos, a flexibilidade de horário de trabalho proporcionava maior tempo com a família, pois são "donas do próprio negócio" e tinham liberdade de escolha de seus horários, como destacado: 
A família amou, porque eu estava em casa mais tempo, aonde eu ia, eu voltava rápido. (R4). Minha prioridade de escolher entrar na empresa foi à flexibilidade de horário [...]. Eu poderia crescer profissionalmente e cuidar dos meus filhos, sem por eles na escola o dia inteiro, foi quando eu vi a flexibilidade de horário e o crescimento que eu poderia ter [...] a gente consegue fazer por nós e no nosso tempo. (R6).

O tempo de atuação na empresa, variou de um ano e sete meses a sete anos. Em relação à renda obtida percebeu-se que os valores informados pelas entrevistadas não estavam diretamente atrelados a quantidade de horas dedicadas ao negócio. Por exemplo: a consultora R1 disse dedicar-se de uma a três horas diária ao negócio e receber de três a seis salários mínimos e, a R2, por sua vez, dedica-se de 11 a 13 horas para obter o mesmo valor. Esta diferenciação pode estar relacionada ao tipo de público alvo atendido. O tempo diário dedicado a empresa depende do nível do cargo/nível, quanto maior, mais tempo é dedicado.

Seis consultoras exerciam outro tipo de atividade remunerada como: proprietária de loja; professora universitária; coordenadora da educação; artesã; auxiliar administrativa; e autônoma (vende outras marcas de produtos), sendo a consultoria de beleza renda extra.

Os dados mostraram que o perfil das entrevistadas se alinhava com a necessidade de flexibilidade e renda extra. Se tal processo pode significar melhores condições de gestão do tempo em função das demandas familiares, por outro se inserem em um quadro mais amplo de precarização do trabalho, conforme abordado por Guimarães (2016). Neste estudo, trata-se de um tipo de flexibilidade que produz uma precariedade objetiva, considerando a fragilidade das relações contratuais associadas a um nível reduzido de proteção social.

\section{Cultura Corporativa: a Formalização dos Valores Desejados}

A administração da cultura ocorre por meio da gestão de três níveis simbólicos: artefatos, valores e crenças (Schein, 1992) e esta perspectiva gerencial da cultura foi também denominada de integração (Martin, 1983) como citado em Hatch (1997). Em tal contexto, a cultura é descrita como tendo orientador valorativo comum para todos os membros da organização, sendo produtora de consensos. A perspectiva da integração (Hatch, 1997) é percebida nos materiais utilizados no processo de socialização de novos membros da organização: kit nova consultora e guia nova consultora.

\section{Kit da Nova Consultora}

Para ingressar na empresa é necessário adiquirir o kit inicial no valor de $\mathrm{R} \$ 169,00$. Neste, está contido o material de apoio à nova consultora e alguns produtos. Tem a função da apresentação (inicial) da empresa à nova entrante, bem como permitir a mesma o acesso as oportunidades oferecidas. De acordo com Siqueira (2006, p. 43-44) a intenção é "criar uma comunidade global e tornar a empresa algo mais do que um simples local de trabalho". Ou seja, para a autora isso corrobora com Maslow, o ser humano necessita pertencer a algo.

\section{Guia da Nova Consultora}

O guia apresenta frases motivacionais como: "Sim! Escolhi uma empresa com valores que eu acredito"; "escolhi fazer parte de uma rede de empreendedorismo feminino global, que existe desde 1963”; entre outros. Além disso, é composto por tópicos intitula- dos de: "saiba onde você quer estar; uma empresa com coração; seu primeiro passo; para começar com tudo; principais ferramentas, sua melhor imagem".

Como plano de valorização e afirmação pessoal, o guia traz uma foto da fundadora da empresa, com a mensagem de empoderamento, reforçando quão incrível ela foi, destacando que ela "acreditava no poder das mulheres". Também apresenta os valores, que ela caracteriza como "vanguardistas". São eles: $1^{\circ}$ regra de ouro (tratar os outros como você gostaria de ser tratada); $2^{\circ}$ espírito de ajuda (ajudar pessoas a se sentirem especiais, apoiando e compartilhando conhecimento com amigas consultoras e com as clientes); $3^{\circ}$ faça me sentir importante (imaginar que as pessoas carregam uma placa invisível com esses dizeres e dar toda atenção a isso); e $4^{\circ}$ equilíbrio de prioridades ("sendo dona do próprio negócio você tem a flexibilidade para colocar Deus em $1^{\circ}$ lugar, sua família em $2^{\circ}$ e sua carreira em $3^{\circ}$ '). Esse aspecto evidencia a identificação da trabalhadora com a organização e seus valores (Davel \& Vergara, 2001).

Nesse guia a empresa também dá "dicas": como ter uma imagem profissional embasando-se na frase "você é a vitrine do seu negócio"; para ter estilo como, por exemplo, "use os produtos Pink Dream; bom humor é tudo". Usar a bolsa oficial das consultoras, uma das marcas registradas das consultoras da marca. Há também um "guia de estilo" em sua página online exclusiva às consultoras. Este evidencia a realização de sessões de beleza, nos quais a consultora deve contatar pessoas para oferecer uma sessão de demonstração dos produtos. Produtos que a nova consultora "ganha" (alguns) quando realiza seu cadastro inicial. Ao fazer o pedido, a empresa "motiva" a compra de outros produtos para demonstração e pronta entrega, seguindo a estratégia "o que você demonstra é o que você vende" e para não perder a venda, a pronta entrega é essencial.

A empresa as estimula e treina a realizar ligações, contato virtual e abordagem fria (abordar pessoas no caminho, entregando amostras e pegando o contato) com a finalidade de agendar sessões. Também, estímulos para a consultora optar em seguir carreira, além das vendas de produtos. Para tanto, a empresa indica um roteiro a ser seguido para apresentar a oportunidade a uma "potencial iniciada": primeiro, deve-se indagar qual é o maior sonho da pessoa; segundo, deve-se perguntar suas prioridades; terceiro, entender o momento de vida em que esta pessoa está; e quarto, perceber as características pessoais. Nos documentos é destacada a frase: "com essas informações em mãos monte um perfil desta pessoa e, imagine quais são os benefícios da carreira independente que vão ajudá-la a realizar seus sonhos seguindo suas prioridades, momento de vida e características pessoais".

A respeito dos reconhecimentos, no documento da empresa, em um trecho especial para as consultoras, destaca: "quando você se torna uma consultora de beleza independente Pink Dream, está predestinada a ter muito sucesso, e ser reconhecida como merece". A empresa faz questão de reconhecer as consultoras. Aqui todo mundo pode brilhar! Basta se planejar! Os prêmios são de arrasar, com itens que qualquer pessoa gostaria de ter. Muitos deles são exclusivos e personalizados como bolsas, malas, óculos, relógios, e até viagens e carros cor de rosa. Já se imaginou dirigindo um desses? Não é o máximo? E o melhor de tudo é que os reconhecimentos da empresa são ilimitados, ou seja, sua amiga vai viajar com você e até subir no palco do seminário com você!

Observa-se que os documentos não se limitam a regras funcionais da atividade das consultoras, pois expressam valores que devem ser incorporados na forma de comportamento e, até mesmo, na autoimagem. A respeito disso, R4 ressaltou a aparência de executiva fortemente evidenciada e quase que institucionalizada na organização. 
Mas eu me estranhei um pouco devido ao perfil de aparência de estar sempre muito arrumada, muito produzida e eu me sentia um pouco desigual do meu esposo. Porque onde eu estava, eu estava sempre de executiva para mais. Eu comecei a me incomodar a partir do momento em que as pessoas tinham o tempo todo esperança em me ver daquela forma e eu não sou daquela forma. (R4).

Ademais, se estabelecem modelos de pessoas que venceram e alcançaram sucesso na organização gerando a ideia de que, é sim possível chegar ao topo basta "desejar" e fazer "um pouco mais". Corroborando com isso, R1 acrescentou que: Tudo é importante, até a caneta para mim é gratificante. Esses aspectos são discutidos por Machado et al. (2016) na perspectiva da cultura corporativa e por Siqueira (2006) quanto as recompensas simbólicas.

Durante algumas entrevistas surgiram aspectos relacionados a existência de um possível estímulo ao "status", no qual muitas vezes as consultoras se esforçam para cumprir metas que não estão ligadas diretamente ao lucro. Mas há algum reconhecimento oferecido, seja ele uma posição de destaque, uma echarpe ou um pin. A respeito disso tem-se que:

Você quer mostrar para as outras pessoas que você trabalhou e que você conseguiu aquilo, e que as coisas acontecem e que você se esforçou muito. (R10); eu tentava sempre adquirir todos, é bem simbólico, quando a gente olhava já não precisava nem dizer se você é consultora na Pink Dream ou não, porque a pessoa te reconhecia tanto pelos pins ou quanto pelos trajes (R9); e você chega num lugar e ás vezes tem uma consultora que sabe onde você chegou, ela pode não saber a sua história, nem seu nome, mas ela sabe onde você está (R7).

Nessa dimensão de análise foram demonstrados os significados construídos pelas trabalhadoras relacionados aos símbolos implantados pela empresa, conforme Davel e Vergara (2001). Portanto, o papel integrador da cultura organizacional operacionalizado pela gestão da cultura corporativa enfrenta a complexidade do contexto social em que se insere (Leite-da-Silva et al., 2006).

\section{Políticas e Práticas da Empresa em Relação às Consultoras: Adaptação à Cultura Organizacional}

Treinamentos. A respeito da participação e frequência nos treinamentos, três consultoras tinham maior frequência, sendo que dessas, uma estava no nível de diretora em qualificação e duas eram diretoras. Para R4 e R5 é importante salientar a importância do foco no negócio nesses níveis. A partir da formação da equipe, a consultora precisa se dedicar mais, já que cabe a ela "treinar e acompanhar" as pessoas do grupo. Portanto, se estabelece uma relação entre treinamento e carreira como forma de confluência do trabalho (Morgan, 2007).

A partir do nível de diretora em qualificação, a consultora passa a ter metas que precisam ser atingidas, caso ela deseje se tornar diretora na empresa, "se você deixar de produzir você também perde todo o trabalho que você fez até ali” (R5). Essa é uma forma da organização estimular as forças produtivas do indivíduo (Pagès et al., 1987).

Uma delas ressaltou que participar dos treinamentos: "é sempre mais incentivador, a gente se sente mais preparada para sair e para atuar no negócio, para entender e conhecer os produtos, é bem inovador" (R9). Todas relataram que após participarem dos treinamentos se sentiram motivadas, estimuladas, com "energias recarregadas" (R10). Esta é a forma da gestão de pessoas alcançar vantagem competitiva (Ávila \& Stecca, 2015; Limongi-França \& Rodrigues, 2013). Com relação ao significado dos treinamentos para suas vidas, todas declararam que representa conhecimento, capacitação, aprendizado, socialização e evolução. Como por exemplo:
Grande conhecimento e que as histórias de vida de cada pessoa trazem bastante pé no chão sobre as dificuldades da vida (R7);

a empresa valoriza todos e consegue dar oportunidades para todos (R4);

e os treinamentos eu vejo eles como crescimento, mas não só para a empresa. Tudo que eu participo relacionado a empresa eu levo para minha vida, eu encaixo sim nas decisões que eu tomo (R1).

Todas afirmaram que ao estarem perto das pessoas que já alcançaram alto nível na organização sentem-se motivadas, é uma inspiração, admiração e aprendizado. Isso foi destacado em:

É realmente como se fosse uma família, porque como a empresa prega uma filosofia e a gente trabalha voltada sobre ela, a gente tem as demais consultoras como se fosse uma família mesmo, quando tem eventos e a gente se encontra é como se fosse uma festa (R9);

e, outro destaque: é grandioso você ver aonde aquela pessoa chegou, como ela chegou e ver que você pode também chegar lá da mesma forma, é maravilhoso. A gente brilha literalmente perto dessas pessoas. O brilho não está só nelas elas levam a gente junto (R7).

O treinamento mencionado pelas consultoras envolveu relatos de histórias de sucesso e a promessa que todos podem "chegar lá", como mencionou a entrevistada R7. Do ponto de vista da cultura organizacional, trata-se de processos de socialização que disseminam os valores pretendidos pela empresa. Freitas (1991) afirma que Schein atribui a transmissão da cultura as oportunidades de aprendizagem entre os membros da organização.

Nessa questão do treinamento como processo de socialização, ficou evidente no depoimento: "me sinto mais entusiasmada, mas na verdade como eu já fui diretora a gente já sabe mais ou menos todos os caminhos" (R5). Ou seja, ela entende que tudo que é repassado nestes treinamentos é questão de estratégia e marketing.

Regulamentos. A respeito da importância de seguir os manuais e diretrizes propostas pela empresa, três consultoras (R5, R9, R10) enfatizaram como sendo muito importante. Destas três, duas relataram ter passado por alguma decepção em relação ao negócio como um todo. R5 e R9 foram diretoras na empresa e, por atingir as metas por meses consecutivos, perderam o cargo e alguns clientes. Esses aspectos retratam regras de comportamento (Freitas, 1991).

De acordo com as diretrizes da empresa, quando uma consultora perde o posto, as pessoas que estão em sua equipe são transferidas para outra de um nível superior. Nesse contexto, a promessa de que todos podem "chegar lá" está condicionada ao cumprimento de metas.

A única consultora que não considerou as regras como "extremamente importante" relatou: "meu foco hoje está voltado para outra coisa" (R10). Isso pode ser explicado pelo fato da empresa não ser seu foco principal. Tratava-se de uma renda extra e não tinha interesse em seguir carreira na empresa. Mais uma vez é evidenciado que "seguir carreira" na organização é algo mais "desafiador" (R3) que requer maior dedicação, até porque, como anteriormente ressaltado, a empresa tem a política de que cabe a iniciadora treinar e acompanhar sua descendente. Em relação a isso, o comentário: "Eu não queria me dar ao trabalho de orientar e ajudar, eu indico para outra consultora” (R10). 
Sete consultoras concordaram ser extremamente importante seguir os manuais e políticas estabelecidas pela empresa. A respeito disso, surgiram ao longo das entrevistas afirmações como: "acho extremamente importante porque se a gente faz à risca tudo que a 'fundadora' coloca para gente, o sucesso é 100\%”, (R1). Esta afirmação remete a ideia de que o sucesso só depende da pessoa e, caso não consiga, é porque fez algo errado, sempre excluindo a culpa da empresa (Siqueira, 2006). Como por exemplo:

Sem elas (as regras) eu não consigo levar o negócio (R4);

"ah! é extremamente importante, a gente tem que andar segundo a cartilha, né”! (R3);

e as regras de conduta a gente têm que levar ao pé da letra para não passar para as outras o que não é certo (R6).

É importante ressaltar que a figura da empresa, para as consultoras, é muito forte, pois todas reconhecem a importância de seguir os manuais. Algumas ainda afirmaram que sem eles é impossível seguir adiante. Isso pode ser reflexo dos constantes treinamentos para fortalecer a cultura organizacional (Marques, 2015).

\section{Relações entre Poder e Identidade no Processo de Gestão}

A cultura organizacional tem estreita relação com a dimensão da identidade. Machado (2003), recorrendo a estudos de Hatch e Schultz (1997), afirma que a cultura oferece material simbólico para os processos de identificação. Questionadas sobre prioridades de suas vidas, para nove delas, a família era uma das prioridades, apenas R7 disse ter como prioridade, "ser feliz". Destas nove, três informaram como prioridades exatamente a ordem de que a empresa se baseia, Deus, família e carreira. Através dessas respostas é possível afirmar que estas consultoras, encontram nas prioridades defendidas pela empresa (símbolos) uma espécie de identificação, visto que a organização defende que todas as pessoas devem ter como prioridades em sua vida Deus, família e carreira. A empresa afirma que sem isso não haverá equilíbrio na vida pessoal. Essa identificação acaba gerando um sentimento de pertencimento, como se a organização fosse algo a mais que um local de trabalho (Siqueira, 2006).

A respeito desse sentimento de pertença surgiram indagações, como:

É realmente como se fosse uma família, porque como a empresa prega uma filosofia e a gente trabalha voltada sobre ela, [...], quando tem eventos e a gente se encontra é como se fosse uma festa (R9);

é um estilo de vida, não é um trabalho. Eu não trabalho Pink Dream, eu vivo 'Pink Dream' [...] Como transformou a minha vida e foi muito bom para mim, eu quero muito isso para as outras pessoas também (R7);

não me vejo não vendendo Pink Dream!; não me vejo sem ela; não seria capaz de largar a empresa; eu sempre fui mais falha com ela do que ela comigo (R1);

e se manter na empresa hoje é não fracassar, eu penso que se eu sair hoje eu vou dizer que eu não fui capaz de levar meu próprio negócio. Eu posso fazer o que eu fizer, mas eu não quero parar (R4).
Em relação à possibilidade de existir alguma conexão espiritual com a cultura da empresa, oito consultoras consideraram que existe. Quatro declararam que a existência dessa conexão as influenciou a entrarem ou permanecerem no negócio. Uma afirmou que "com certeza essa conexão me influenciou a entrar no negócio" (R1), para ela a relação entre o trabalho e crença devem estar unificadas.

Com certeza, a gente exercendo a filosofia da empresa que é Deus em $1^{\circ}$ lugar, a gente acaba sendo pessoas melhores, com certeza existe essa conexão e ela me ajudou a entrar no negócio (R9); e existe totalmente essa conexão e isso me influenciou a me manter no negócio (R7).

Tais afirmações corroboram com Souto e Rego (2006), ao retratarem que o estímulo a espiritualidade, abordado no ambiente organizacional, ocasiona maior desempenho individual e organizacional. A consultora R7 complementou que a filosofia da empresa:

Traz muita espiritualidade, te faz crescer como pessoa e como profissional e não só te faz ganhar dinheiro [...]. A gente ganha dinheiro ajudando outras pessoas, isso que me mantém na empresa [...] e é ajudando outras pessoas a melhorarem e transformarem suas vidas que a gente está melhorando a nossa (R7).

Tal afirmação corrobora com Dejours (2004) que o indivíduo encara o trabalho como algo a mais que o faz se sentir útil e, cada vez menos, consegue separar a vida pessoal da profissional, fazendo com que o trabalho esteja presente na maioria ou em todos os momentos. A entrevistada R7 ainda afirmou que trabalhar na empresa "é mais um estilo de vida do que uma profissão, a gente não só trabalha".

Processos de identidade com os valores organizacionais podem representar formas de introjeção da cultura organizacional, mas também riscos. Machado (2003) afirma que: O sentimento de identificação do indivíduo com a organização atua como fonte simbólica de proteção, desencadeando processos emocionais, que tendem a contribuir para a criatividade no trabalho; no entanto, uma identificação muito intensa pode resultar em interferência negativa na construção da identidade porque, para uma identidade estar bem consolidada, é necessário que exista uma fronteira simbólica entre o eu, o grupo, o trabalho e a organização.

A consultora R4, uma das duas entrevistadas que afirmaram não haver conexão entre a organização e aspectos religiosos, ressaltou que:

Na verdade, eles criaram o tripé: Deus, família e carreira, mas eu uso o tripé ao contrário. Porque na empresa se você não se dedicar em $1^{\circ}$ lugar à carreira, você não consegue levar ela a diante, porque ela suga bastante, se você realmente quiser conquistar o que ela te oferece. Mas ela diz que você não pode usar a empresa em $1^{\circ}$ lugar, porque ela foi feita para você simplesmente se sentir útil para alguma coisa. Acho que ela passa valores importantes, como: ser mulher e auxiliar outras mulheres a ficarem mais bonitas, mas pregação ou doutrinação espiritual não, mas sim uma energia muito positiva, a gente se sente melhor (R4).

Diante dessa afirmação, mesmo a consultora não concorde que existam aspectos simbólicos envolvendo a organização, é possível afirmar a existência, uma instrumentalização da espiritualidade, a fim de estimular nas colaboradoras a ideia de "entidade superior", de trazer significado para vida, sentindo-se útil na re- 
alização de seus projetos. "A empresa (ou qualquer outra organização) quer, nos dias de hoje, encarnar 'a instituição divina'. Esse sagrado laico que dá ao indivíduo o sentimento de transcender por um projeto ou um ideal a realizar, uma causa a defender" (Davel \& Vergara, 2001, p. 175).

Os principais fatores citados a respeito do por que entraram para a empresa foram: liberdade, flexibilidade de horários, renda extra, qualidade dos produtos e consumir mais barato. A cultura organizacional presente na empresa se mostra forte, pois algumas consultoras relataram que não se imaginam viver sem ela.

Não me vejo não vendendo Pink Dream; "Não me vejo sem ela";

"Não seria capaz de largar a empresa. (R1);

e sem manter na empresa hoje é não fracassar, eu penso que se eu sair hoje eu vou dizer que eu não fui capaz de levar meu próprio negócio. Eu posso fazer o que eu fizer, mas eu não quero parar[...](R4).

Aspectos retratados por Pinto (2011) e Souza et al. (2015), como por exemplo: eu sempre fui mais falha com ela do que ela comigo (R1). Outras declarações:

Eu ofereço porque eu quero que as outras pessoas cresçam como eu cresci. E não é só o crescer financeiramente, a gente cresce em outras áreas da vida. [...] Eu larguei o serviço só para fazer Pink Dream e isso foi gratificante [...] quebrou muitos paradigmas meus. O que mais me encanta é enriquecer vidas (R1);

eu poderia estar ajudando novas pessoas, com certeza aquela pessoa passaria a ter uma vida financeira melhor e isso ela realizaria o sonho dela, automaticamente eu realizaria o meu (R9);

e como transformou a minha vida e foi muito bom para mim, eu quero muito isso para as outras pessoas também. Tem muita gente que precisa de uma oportunidade como essa. Quando aceita iniciar fico muito feliz, não só pelo ganho que temos, mas conforme a gente vai fazendo essa pessoa crescer ensinando ela, a conhecer, a gente também vai ganhando, claro. Mas é vendo que ela pode se transformar [...] as pessoas da minha equipe são muito mais felizes, mais alegres, mais carinhosas (R7).

Para Souto e Rego (2006), a partir de determinado momento o trabalho passa a ser entendido e encarado como vocação, facilitando a imersão do colaborador na empresa, já que o mesmo passa a "se entregar de corpo e alma". Essa obstinação por ajudar pessoas e "enriquecer vidas" faz com que eles se considerem "um herói moderno inscrevendo-se no mito coletivo da organização" (Davel \& Vergara, 2001, p. 175). Destaque foi dado:

Vivi uma experiência inovadora, lidar com o negócio foi um desafio. Eu cresci como pessoa, amadureci, me tornei uma pessoa mais responsável financeiramente e independente (R10); acho maravilhoso não ter chefe, vou e volto na hora que eu quero, eu determino onde eu quero chegar. Meu salário eu que faço. Acho que é o sonho de todo mundo ser dona do próprio negócio. Ser dona do próprio negócio representa liberdade. $O$ que mais me encanta é o tripé da empresa $1^{\circ}$ Deus, $2^{\circ}$ família e $3^{\circ}$ carreira (R7).
Rego, Cunha e Souto (2007) descrevem que o ser humano se sensibiliza facilmente a temas relacionados a liberdade, justiça, confiança, tratamento respeitador e digno. Quanto ao estímulo a outras pessoas:

Não continuo oferecendo a oportunidade, mas já fiz muito isso. Eu oferecia porque eu estava bem incentivada, eu sabia que tinha um crescimento na empresa, mas para isso acontecesse eu tinha que ajudar demais pessoas a querer chegar no mesmo objetivo que eu [...]. Quando a pessoa não aceita entrar para o negócio eu respeitava e imaginava que um dia ela possa entender a oportunidade do negócio e aceitar entrar (R9).

Para Foucault (1979), questões objetivas e subjetivas do sujeito são modificadas de acordo com as experiências. As experiências vividas em relação à organização contribuem para que as colaboradoras se tornem defensores ou acusadores da mesma. Nesse caso R9 acreditava tanto na empresa que, quando alguém não aceitava entrar para o negócio, imaginava que a pessoa não devia ter entendido a oportunidade, porque se a tivesse, não pensaria duas vezes.

\section{Adaptação, Realização e Reconhecimento}

Todas as consultoras estavam satisfeitas com a empresa e, entrariam novamente neste negócio. Entretanto, R5 e R9 disseram que não entrariam para iniciar novamente uma carreira, se dedicariam apenas as vendas. Isso pode ser explicado pelo fato delas já terem sido diretoras e perdido o cargo por não cumprirem as metas. "Porque é uma carreira desafiadora, onde você não tem solidez [...] Então não adianta você nadar, nadar e morrer na praia" (R5).

A respeito das mudanças obtidas na vida pessoal e profissional, todas frisaram que desde seu ingresso obtiveram mudanças, consideradas por elas, como positivas:

Eu olho até minhas fotos antigas e teve uma mudança muito grande [...] eu aprendi a me amar mais! (R1);

cresci muito como pessoa, eu amadureci, me tornei uma pessoa mais responsável financeiramente e independent (R10); realização de sonhos (R9);

mudou tudo! Hoje eu enxergo a vida de uma maneira totalmente diferente, no começo eu reclamava muito, mudanças radicais! [...]. Foi uma reviravolta (R7);

oportunidade de poder mostrar algo que eu como dona de casa jamais faria (R5);

e eu trabalho motivada! Eu posso estar capengando de doente e posso estar entristecida, mas a hora que eu saio para a rua tudo muda (R6).

Fatores relacionados a liberdade, motivação, reconhecimento, independência financeira e amor próprio foram ressaltados. Isso corrobora com Souto e Rego (2006) que uma organização que estimula a espiritualidade e motivação, no contexto de trabalho, consegue alcançar maiores desempenhos individuais e organizacionais.

Todas as consultoras destacaram a aquisição de bens desde que iniciaram na empresa e, ser membro da mesma foi, no mínimo, importante para alcançar estes. Todas também afirmaram lucrar com a empresa, mas ao serem questionadas se conhecem 
o valor exato desse lucro, R5 e R10, informaram não saber. As demais pesquisadas afirmaram que realizam seu controle pessoal e têm propriedade sobre esses lucros. Entretanto, durante as entrevistas percebeu-se que a maioria delas se toma como referência para controle o lucro que a empresa diz, ou seja, nas porcentagens de desconto que atingem no momento do pedido.

Em relação aos reconhecimentos, todas afirmaram tê-los recebido da empresa. Foram citados como forma de reconhecimento, bolsas, joias, viagens, participação de destaque no evento nacional da empresa, pins e demais acessórios. Todas também foram unânimes em dizer que, hoje são pessoas melhores do que eram antes de entrar na empresa e que a autoestima mudou:

Quando você consegue produzir algo e ver que você é capaz e de que aquilo depende de você, você se sente mais segura e confiante (R5);

eu passei a gostar mais de mim, a enxergar minhas qualidades (R10);

hoje eu sou mais feliz com o meu trabalho (R6);

e eu não me maquiava, eu não cuidava do cabelo, teve um resgate de mim mesma! Eu aprendi que quando a gente vende um produto a gente tem que mostrar e qual a cara do produto? A sua (R1).

Esses resultados reforçam Bertero (2007), mesmo sendo usada de forma manipuladora, a espiritualidade estimulada no trabalho ajuda o colaborador a aumentar sua satisfação com a empresa, lealdade, franqueza, respeito e autoestima.

Analisando a valorização, apenas R5 não se sentia tão valorizada. Concordou que a empresa a valorizava, mas “... a forma como os gestores realizam a gestão não a faz se sentir valorizada”, ou seja, a culpa não era da empresa em si, mas dos gestores (pessoas que se encontram em níveis superiores, como diretora nacional, por exemplo). Esse sentimento pode ser explicado pelo fato de ter deixado de ser diretora da empresa e, por este motivo, as superioras acabaram não demonstrando tanta atenção, pois não mais as convém.

As demais relataram se sentirem valorizadas quando a empresa as reconhece pelo esforço e dedicação, fazer o que gosta, quando as clientes são fieis e quando as outras consultoras oferecem ajuda. Vergara e Moura (2012, pp. 11) destacam que a inserção da espiritualidade no contexto de trabalho se dá pela valorização “[...] do ser humano [...]; da autoestima das pessoas; [...] da cooperação ao invés do acirramento entre os membros da organização; laços de confiança; um ambiente de trabalho marcado pela alegria e harmonia $[\ldots .$. ".

Ao serem questionadas sobre não conseguir alcançar algum reconhecimento pela empresa, as consultoras disseram sentirem-se tristes, entretanto, de modo geral, se sentiam desafiadas a renovarem suas metas e estratégias. Além disso, foram unânimes em ressaltar que quando não conseguem é porque não trabalham o suficiente e, em nenhum momento, atrelaram a incapacidade de sucesso ao tamanho da meta, por maior e impossível que ela seja (Siqueira, 2006). Surgiram relatos como:

Eu sempre fui mais falha com a empresa do que ela comigo (R1);

algo eu deixei de fazer, não fiz o suficiente (R9);

procrastinação (R7); eu mesma me impedi (R5);

poderia ter feito um pouco mais (R2);

falta de foco (R3);

e deveria ter planejado mais, porque se duas ou três consegue é possível você conseguir (R8).

Em relação a algum reconhecimento que tenha sido mais importante, R1, R3 e R8 ressaltaram que todos foram importantes. As outras destacaram reconhecimentos como: viagens (R2), mesmo que ela não tenha ido por conta da gestação; R9 descreveu que ganhar o título de "rainha de vendas da unidade de sua diretora”, é um mérito, porque você trabalhou e a empresa reconheceu. "Quando a gente recebe um e-mail parabenizando pela mudança de nível; cada degrau que você sobe na carreira" (R7).

A partir dos relatos percebe-se o quanto a simbologia do reconhecimento torna-se mais importante do que seu valor financeiro e, mesmo quando as consultoras apenas cadastram pessoas para atingir números em busca de algum reconhecimento, ainda se sentem vitoriosas. Isso está relacionado com necessidades sociais, de estima e de autorrealização de Maslow.

Dessa forma Souza et al. (2015) afirmam que através da cultura organizacional as empresas introduzem mecanismos que constroem o modo de ser em suas equipes. Pagès et al. (1987, p. 27-28) complementam que ao disponibilizar "satisfação econômica”, "psicológica", "satisfações morais", "momentos de prazer e responsabilidades", as forças produtivas são totalmente voltadas aos objetivos da organização e do capitalismo.

\section{Considerações Finais}

Os resultados obtidos revelaram forte identidade das trabalhadoras com a proposição da cultura corporativa, principalmente em função da possibilidade de liberdade, flexibilidade de horários, renda extra, qualidade dos produtos e consumir mais barato. Outro fator importante relatado pelas entrevistadas refere-se a dimensão simbólica do reconhecimento.

Percebeu-se que os manuais e treinamentos expressam de forma intensiva traços culturais que fortalecem essa adesão, principalmente apoiados em histórias de sucesso e formas de reconhecimento materiais e simbólicas. Certos relatos mostraram que algumas consultoras estabelecem limites para essa adesão, ao escolher um envolvimento parcial com a cultura, ou mesmo fazendo críticas a ação dos gestores, os depoimentos revelam uma forte adesão econômica e valorativa em relação à empresa.

Assim, os traços da cultura corporativa são traduzidos positivamente pela cultura organizacional, sendo que os limites entre eles são bastante tênues. Uma das possibilidades que pode explicar essa forte adesão é o fato dos novos membros serem trazidos pelas trabalhadoras atuais que tem maior identidade com a cultura da empresa.

Embora a cultura corporativa seja bem direcionada por meio de documentos amplamente utilizados no processo de socialização e desenvolvimento das trabalhadoras da organização, os dados indicaram que o êxito da adesão ao projeto organizacional ocorre por uma aproximação muito forte entre cultura corporativa e organizacional. A primeira difundida e enraizada nos processos de socialização e treinamento por meio de manuais, regras e rituais e, a segunda, por um trabalho de seleção bastante focado em um perfil que coaduna com o enlace dessas duas dimensões da cultura (organizacional e corporativa). As trabalhadoras que expressaram maior identidade foram aquelas que almejavam as condições de 
trabalho apresentadas nos valores, quais sejam, autonomia, flexibilidade e reconhecimento.

As limitações do estudo ocorreram em função da dificuldade no acesso e disponibilidade de tempo das consultoras para participar da pesquisa. Sugere-se que novos estudos sejam realizados no âmbito da estratégia de gamificação, visivelmente proposta e implementada pela empresa e, também, em relação a consultoras que passaram por processos desmotivadores, como por exemplo, desceram de nível na hierarquia da empresa. Outro aspecto é estudar que tipo de qualificação para planejamento financeiro em relação a estoque de produtos é dado e como as consultoras tem gerenciado isso. Neste sentido, identificar o real motivo, possíveis sentimentos de aversão e desmotivação frente à organização se mostra relevante.

\section{Referências}

Abilio, L. C. (2011). O make up do trabalho: uma empresa e um milhão de revendedoras de cosméticos (Tese de doutorado, Universidade Estadual de Campinas, Campinas, SP, Brasil). Recuperado de http://repositorio.unicamp.br/ handle/REPOSIP/280166

Alves, G. (2018). Brasil: O Futuro do Pretérito-Notas Sobre as Perspectivas do Trabalho no Século XXI. Em E. Macário (Org.), Dimensões da crise brasileira: dependência, trabalho e fundo público ( $1^{\mathrm{a}}$ ed., pp. 57). Fortaleza, EdUECE.

Antunes, R., \& Praun, L. (2015). A sociedade dos adoecimentos no trabalho. Serviço Social \& Sociedade, (123), 407-427. https://doi.org/10.1590/0101$\underline{6628.030}$

Ávila, L. V., \& Stecca, J. P. (2015). Gestão de pessoas. Santa Maria: Universidade Federal de Santa Maria, Colégio Politécnico Rede e-Tec Brasil.

Barbosa, L. (2001). Igualdade e meritocracia: a ética do desempenho nas sociedades modernas. FGV Editora.

Bedani, M., \& Veiga, H. M. S. (2015). Práticas organizacionais: uma contribuição teórica. Gerais: Revista Interinstitucional de Psicologia, 8(2), 428442. Recuperado de http://pepsic.bvsalud.org/scielo.php?script=sci arttext\&pid=S1983-82202015000300011

Bertero, C. O.(2007). A permanência da religião. GV Executivo, São Paulo, FGV, 6(6), 64-68. https://doi.org/10.12660/gvexec.v6n6.2007.34741

Davel, E., \& Vergara, S. C. (2001). Gestão com pessoas, subjetividade e objetividade nas organizacões. Gestão com pessoas e subjetividade. Atlas, 31-56.

Dejours, C. (2004). Subjetividade, trabalho e ação. Production, 14(3), 27-34. https://doi.org/10.1590/S0103-65132004000300004

Foucault, M. (1979). Microfísica do poder. Rio de Janeiro: Edições Graal, 4.

Freitas, M. E. D. (1991). Cultura organizacional grandes temas em debate. Revista de Administração de empresas, 31(3), 73-82. https://doi.org/10.1590/S003475901991000300007

Guimarães, N. A. (2016). A igualdade substantiva e os novos desafios nas relações de gênero no trabalho. Revista Estudos Feministas, 24(2), 639-643. https://doi. org/10.1590/1805-9584-2016v24n2p639

Hatch, M. J. (1997). Organization theory. New York: Oxford University Press.

Hatch, M. J., \& Schultz, M. (1997). Relations between organizational culture, identity and image. European Journal of marketing, 31(5-6), 356-365. https:// doi.org/10.1108/eb060636

Hirata, H. (2015). Globalização, trabalho e gênero. Revista de Politicas Públicas, 9(1),111-128. Recuperado de http://www.periodicoseletronicos.ufma.br/ index.php/rppublica/article/view/3770

Hofstede, G. (1980). Culture and organizations. International Studies of Management \& Organization, 10(4), 15-41. https://doi.org/10.1080/00208825.1980.116 $\underline{563000}$

Leite-da-Silva, A. R., Junquilho, G. S., Carrieri, A. D. P., \& Melo, M. C. O. L. (2006). Contradições gerenciais na disseminação da "cultura corporativa": o caso de uma estatal brasileira. Revista de Administração Pública, 40(3), 357-384. https://doi.org/10.1590/S0034-76122006000300003

Limongi-França, A. C., \& Rodrigues, A. L. (2013). Stress e trabalho: uma abordagem psicossomática ( $\left.4^{\mathrm{a}} \mathrm{ed}\right)$. Atlas.

Machado, F. C. L., Maranhão, C. M. S. D. A., \& Pereira, J. J. (2016). O conceito de cultura organizacional em Edgar Schein: uma reflexão à luz dos estudos críticos em Administração. Recuperado de https://www.repositorio.ufop.br/bitstream/1 23456789/8110/1/ARTIGO ConceitoCulturaOrganizacional.pdf

Machado, H. V. (2003). A identidade e o contexto organizacional: perspectivas de análise. Revista de Administração Contemporânea, 7(SPE), 51-73. https://doi. org/10.1590/S1415-65552003000500004

Marques, J. C. (2015). Gestão de Recursos Humanos. Cengage Learning Editores.

Morgan, G. (2007). Imagens da organização: edição executiva. Em Imagens da Organização: edição executiva.

Oncken, A. N., Pedroso, A. C., Sampaio, M. C. C., Barbosa, T. C., \& Fischer, M. (2012). Mary Kay Brasil: ações promocionais para venda direta. Revista
Temática, 8(2),1-11.

Pagès, M., Bonetti, M., De Gaulejac, V., \& Descendre, D. (1987). O poder das organizações: a dominação das multinacionais sobre os indivíduos. Atlas.

Pinto, V. R. T. (2011). Análise do discurso organizacional em uma empresa de marketing multinivel: um estudo de caso. Recuperado de http://bdm.unb.br/ handle/10483/1493

Raposo, R. J. D. A. M. (2020). Modelos operativos da cultura organizacional. Lusíada. Economia \& Empresa, 28, 149 -232. https://doi. org $/ 10.34628 / 79 \mathrm{mc}-w n 49$

Rego, A., Cunha, M. P. E., \& Souto, S. (2007). Espiritualidade nas Organizações e Comprometimento Organizacional. RAE - eletrônica, 6(2).

Reis, G. G., \& Azevedo, M. C. D. (2015). Relações entre autenticidade e cultura organizacional: o agir autêntico no ambiente organizacional. RAM, Rev. Adm. Mackenzie, São Paulo, 16(6), 48-70. https://doi.org/10.1590/167869712015/administracao.v16n6p48-70

Ronchi, C. C., Bandeira, N., Melo, J. S. Jr., \& Oliveira, R. D. (2016). O Discurso Organizacional: Constructo Sedutor para Apreensão de Talentos. Revista Espacios, 37(17). Recuperado de https://www.revistaespacios.com/ a16v37n17/16371720.html

Schein, E. H. (1984). Culture as an environmental context for careers. Journal of Organizational Behavior, 5(1), 71-81. https://doi.org/10.1002/job.4030050107

Sennet, R. (2001). A corrosão do caráter: as consequências pessoais do trabalho no novo capitalismo. Rio de Janeiro: Record.

Siqueira, D. D. C. O. (2006). Corpo, comunicação e cultura: a dança contemporânea em cena. Campinas, SP: Autores Associados. Coleção Educação Física e Esportes.

Souto, S. D. O., \& Rego, J. A. (2006). Espiritualidade nas organizações, positividade e desempenho. Anais do Encontro Nacional da Associação Nacional de Pós-Graduação e Pesquisa em Administração.

Souza, S. P., Oliveira, M. E. C. D, \& Da Silva, P. D. O. M. (2015). A produção de discursos em uma empresa de cosméticos: um sonho rosa. Farol-Revista de Estudos Organizacionais e Sociedade, 2(3), 11-70. https://doi.org/10.25113/ farol.v2i3.2525

Tavares, M. A. (2015). O trabalho informal e sua suposta autonomia: uma modalidade flexível de exploração. Revista Direitos, Trabalbo e Política Social, 1(1), 39-58. Recuperado de http://revista91.hospedagemdesites.ws/index. $\mathrm{php} / \mathrm{rdtps} / \mathrm{article} / \mathrm{view} / 3$

Vasconcelos, I. F. G. D., \& Vasconcelos, F. C. D. (2003). Identidade, legitimação social e teoria organizacional: contribuições de uma análise sociológica da política de gestão de pessoas da Natura. Organ. Soc, 10(27), 41-59. https:// doi.org/10.1590/S1984-92302003000300003

Vergara, S. C., \& Moura, L. S. (2012). Práticas de espiritualidade na gestão de pessoas. Negócios e Talentos, 7(7), 51-74.

\section{Informações sobre os autores:}

\section{Amanda Dourado Espíndola}

Rua Alzemiro Figueiredo da Silva, 150, Vila Vargas

79878-000 Dourados, MS, Brasil

E-mail: amandaespindola19@hotmail.com

\section{Erlaine Binotto}

E-mail: erlainebinotto@ufgd.edu.br

Elisabete Stradiotto Siqueira

E-mail: betebop@ufersa.edu.br

\section{Eduardo Luis Casarotto}

E-mail: eduardocasarotto@ufgd.edu.br 